\title{
Impact of breast cancer and quality of life of women survivors
}

\author{
Impacto do câncer de mama e qualidade de vida de mulheres sobreviventes \\ Impacto del cáncer de mama y calidad de vida de mujeres sobrevivientes
}

\section{Julia Viana Lopes', Cristiane Decat Bergerot', Luciene Rodrigues Barbosa', Nilciza Maria de Carvalho Tavares Calux", Simone Elias", Kimlin Tam Ashing'"I, Edvane Birelo Lopes de Domenico'}

\author{
' Universidade Federal de São Paulo, Paulista School of Nursing. São Paulo, São Paulo, Brazil. \\ "Universidade Federal de São Paulo, Paulista School od Medicine. São Paulo, São Paulo, Brazil. \\ II'City of Hope Medical Center. Duarte, California, United States of America.
}

How to cite this article:

Lopes JV, Bergerot CD, Barbosa LR, Calux NMCT, Elias S, Ashing KT, et al. Impact of breast cancer and quality of life of women survivors. Rev. Bras. Enferm. [Internet]. 2018;71(6):2916-21. DOI: http://dx.doi.org/10.1590/0034-7167-2018-0081

\section{ABSTRACT}

Objective: To evaluate the impact of breast cancer and the quality of life of women survivors and to identify associations between sociodemographic and clinical variables. Method: This was a cross-sectional, analytical, quantitative study conducted with women receiving outpatient post-treatment care at a public institution of the city of São Paulo, state of São Paulo, Brazil. Instruments: sociodemographic and clinical questionnaires; Impact of Cancer scale; Functional Assessment of Cancer TherapyBreast Cancer scale. Descriptive and analytical statistical analysis were performed. Results: One hundred women were included in the study with a mean age of 60 years $(S D=11.3)$; most with less than 5 years of follow-up, low purchasing power, and low education levels. Negative Impact of Cancer: Health Worry, Body Changes, Feelings, and Meaning of Cancer. Quality of life: 81.9 (18.3), specific: 105.6 (24.6). The following subscales of the impact of cancer scale predicted lower quality of life scores: Body Changes, Negative Self-Evaluation, and Concerns about Cancer ( $p<0.05)$. Conclusion: Although they presented high scores for quality of life, patients reported negative impacts of cancer, enhanced by vulnerabilities.

Descriptors: Breast Neoplasms; Survivors; Quality of Life; Sickness Impact Profile; Oncology.

\section{RESUMO}

Objetivo: Avaliar o impacto do câncer de mama e a qualidade de vida de mulheres sobreviventes e identificar associação de variáveis sociodemográficas e clínicas. Método: Transversal, analítico, quantitativo, com mulheres pós-tratamento ambulatorial de câncer de mama em instituição pública do município de São Paulo, São Paulo, Brasil. Instrumentos: sociodemográfico e clínico; escala Impacto do Câncer; Functional Assessment of Cancer Therapy-Breast Cancer. Análise estatística descritiva e analítica. Resultados: 100 mulheres, média de 60 anos ( $\mathrm{DP}=11,3)$; maioria em seguimento inferior há 5 anos, baixo poder econômico e escolaridade. Impacto do Câncer negativo: Preocupação com a Saúde, Mudanças Corporais, Sentimentos e Significado do Câncer. Qualidade de Vida: 81,9 (18,3), específico: 105,6 (24,6). Subescalas do impacto do câncer que predisseram piores escores de qualidade de vida : Mudanças Corporais, Autoavaliação Negativa e Preocupação com o Câncer $(p s<0,05)$.Conclusão: Apesar de apresentarem um bom escore de qualidade de vida, pacientes reportaram impacto negativo do câncer, agravado por vulnerabilidades.

Descritores: Neoplasias da Mama; Sobrevivente; Qualidade de Vida; Perfil de Impacto da Doença; Oncologia.

\section{RESUMEN}

Objetivo: Evaluar el impacto del cáncer de mama y la calidad de vida de mujeres sobrevivientes, identificar asociación de variables sociodemográficas y clínicas. Método: Transversal, analítico, cuantitativo, con mujeres post-tratamiento ambulatorio de cáncer de mama en institución pública del municipio de São Paulo, São Paulo, Brasil. Instrumentos: Sociodemográfico y clínico; Escala Impacto del Cáncer; Functional Assessment of Cancer Therapy-Breast Cancer. Análisis estadístico descriptivo y analítico. Resultados: Cien mujeres, media etaria de 60 años $(S D=11,3)$, mayoría en seguimiento inferior a 5 años, bajos recursos y escolarización. Impacto del Cáncer negativo: Preocupación por la Salud, Cambios Corporales, Sentimientos y Significado del Cáncer. Calidad de Vida: 81,9 (18,3), específico: 105,6 (24,6). Subescalas del impacto del cáncer predictoras de peores puntajes de calidad de vida: 
Cambios Corporales, Autoevaluación Negativa y Preocupación por el Cáncer ( $p s<0,05)$. Conclusión: Aun presentando buenos puntajes de calidad de vida las pacientes informaron impacto negativo del cáncer, agravado por sus vulnerabilidades.

Descriptores: Neoplasias de la Mama; Sobrevivientes; Calidad de Vida; Perfil de Impacto de Enfermedad; Oncología.

\section{CORRESPONDING AUTHOR Cristiane Decat Bergerot E-mail: crisbergerot@gmail.com}

\section{INTRODUCTION}

In the United States there are more than 12 million cancer survivors and by the year 2024, this figure is estimated to reach 19 million $^{(1)}$. This increase is caused primarily by the technological advances achieved in early and histopathological diagnosis, as well as the discovery of new drugs, and the increase of therapies that allow healing and/or control of the disease $\mathrm{e}^{(1)}$.

In Brazil, breast cancer is the most common malignant disease affecting women since $1979^{(2)}$. In 2012, 52,680 new cases of breast cancer and approximately 12,000 deaths were registered, pointing to precarious oncological care nationwide ${ }^{(2)}$. Due to the continental dimensions of the country and the unequal distribution of per capita income, the greatest possibility of early diagnosis and adequate therapy institutions are found in the South and Southeast regions of the country, which concentrate the best cancer treatment centers ${ }^{(3)}$.

From a biopsychosocial point of view, receiving a breast cancer diagnosis negatively impacts a woman's life, with common feelings of fear and suffering throughout the entire process, including the diagnostic, therapeutic and survival phases. In general, post-treatment patients, whether surgical or clinical (antineoplastic chemotherapy, radiotherapy, endocrine therapy), continue with consultations, or follow-up visits, for up to 10 years, regardless of endocrine therapy indication ${ }^{(4-5)}$.

The concept of "cancer survivor" emerged in the United States and was first coined in 1996 by the National Coalition for Cancer Survivorship. By definition, a survivor is any individual with cancer, from the time of diagnosis until the later years, regardless of the outcome; i.e, with chronic disease or disease-free ${ }^{(5-6)}$. The concept was later expanded by the Centers for Disease Control and Prevention to include family members, friends, and caregivers as secondary survivors; while also categorizing survivors according to phase and time ${ }^{(6)}$.

Although absolutely desirable, surviving cancer requires the maintenance of care that should be systematically included in follow-up visits. Survivors are exposed to a number of situations, including risk of cancer recurrence and/or second malignant neoplasm (due to cancer treatment, genetic factors or longevity), late side effects, and/or co-morbidities arising from treatments, from some physical sequelae such as cardiac, pulmonary problems and fatigue, including depression and post-traumatic stress disorder ${ }^{(5-8)}$. There is also the need to acquire and/or maintain behaviors to promote health and psychosocial well-being ${ }^{(5,7)}$.

The quality of life (QoL) of women who are breast cancer survivors has been extensively studied worldwide, with different ethnicities and vulnerabilities considered ${ }^{(8-9)}$. Even though there has been considerable improvement in the general QoL of these women, some problems in the social/familial, emotional, spiritual and physical domains persist, specifically regarding memory and concentration, pain, lymphedema, sexual performance, and self-image. Negative impacts on these domains have been identified in the period between 5 and 10 years after diagnosis. For a contextualized analysis, studies recommend extending the evaluation to include social, environmental, cultural, economic, life burden aspects, among others ${ }^{(8-10)}$.

There is little information about breast cancer survivors in the Brazilian population and, considering national investments to improve the number of early diagnoses and the provision of adequate treatment in the last decades, data need to be checked. Thus, the present study was based on the following guiding research questions: How do women breast cancer survivors evaluate their QoL? What was the impact of cancer on their lives? What sociodemographic and clinical variables are associated with quality of life and impact of cancer?

\section{OBJECTIVE}

To assess quality of life and to measure the impact of cancer of women who survived breast cancer at least 12 months after the end of primary treatment, and to identify sociodemographic and clinical variables associated with QoL and impact of cancer.

\section{METHOD}

\section{Ethical aspects}

The study met the ethical recommendations and was approved by the Ethics and Research Committee of the Federal University of São Paulo - UNIFESP.

\section{Study design, setting and period}

This was a cross-sectional and analytical study, conducted between February 2016 and August 2017, at the Mastology Outpatient Clinic of the Federal University of São Paulo, UNIFESP. On average, 60 new patients/year with a diagnosis of breast cancer are cared for at the clinic, which provides surgical and clinical treatment, including antineoplastic chemotherapy, radiotherapy, and endocrine therapy to the patients of the Brazilian Unified Health System (SUS).

\section{Population, inclusion and exclusion criteria}

The convenience sample consisted of patients who met the following inclusion criteria: breast cancer of any etiology, 18 years or older; with or without endocrine therapy, and who had completed primary treatment and had been receiving clinical follow-up care for at least 12 months from the date of the last therapeutic procedure (chemotherapy, antineoplastic, radiotherapy or surgical). The exclusion criteria were: patients with active disease, psychiatric comorbidities or cognitive deficits recorded in the medical chart, and who presented any other inability to respond to the instruments.

\section{Study protocol}

After signing the Informed Consent Form, the patients were interviewed in the outpatient clinic waiting room while waiting 
for a follow-up medical appointment. The researchers read the items on the instrument and recorded the answers only when participants had any doubts. The average administration time was 20 minutes. No participants dropped out during data collection or over the course of the study.

\section{Data collection and instruments}

Three instruments were used, and the first gathered sociodemographic and clinical data regarding age, gender, marital status, level of education, social class, year of diagnosis, type of cancer, clinical staging of the disease, and treatment performed. Data available in electronic health records were used to complete the clinical information. Next, two instruments were chosen: the Impact of Cancer (IOC) scale and the Functional Assessment of Cancer Therapy-Breast Cancer (FACT-B), both authorized for use:

Impact of Cancer: a translated and validated version of the Impact of Cancer (IOC) scale ${ }^{(11)}$ transculturally adapted to the Portuguese language by Mendes et al. ${ }^{(12)}$. This adapted version consists of 31 items divided into seven subscales: health worry, body changes, feelings about cancer, negative self-evaluation, negative outlook, meaning of cancer, concerns about cancer. For each item there are Likert-like alternatives, 5 points ( $1=$ strongly disagree, $2=$ disagree, $3=$ neutral, $4=$ agree and $5=$ strongly agree). To evaluate the impact of cancer, each subscale is scored by calculating the average score of the answers to the items that make up the subscale. Thus, a mean value above 3.0 indicates greater IOC.

Quality of Life: a translated and validated Portuguese version of the Functional Assessment of Cancer Therapy-Breast Cancer (FACT-B) ${ }^{(13)}$, consisting of 27 items that evaluate physical well-being (seven items, score 0-28), social/family well-being (seven items, score 0-28), emotional well-being (six items; score 0-24), functional well-being (seven items, score 0-28) and additional concerns (10 items, 0-40 score). The scores of each domain are summed up, and the maximum total is 108 points. The higher the score, the higher the quality of life ${ }^{(13)}$.

\section{Analysis of results and statistics}

Sample characteristics were processed using descriptive statistics that analyzed the frequencies, means and standard deviations of the variables studied. Considering that the validation occurred with a population with colorectal cancer (11), Cronbach's alpha was applied to estimate the reliability of the IOC instrument, which presented good internal consistency in the present sample ( $\alpha=0.83$ ). Linear regression was performed to identify the potential factors associated with the impact of cancer, including sociodemographic, clinical and quality of life variables. All analyses were performed with the Statistical Package for the Social Sciences (SPSS), version 22.0 for MAC.

\section{RESULTS}

A total of 100 women participated in the study, with a mean age of 59.1 years ( $35-88$ years, $\mathrm{SD}=10.6)$, most of them married $(50 \%)$, with complete elementary school $(60 \%)$, belonging to social class C (63\%), unemployed and/or retired (77\%). Regarding habits, 5\% declared to be smokers and $6 \%$ alcoholics. The most frequent type of cancer was ductal carcinoma (49\%). Most patients (76\%) were diagnosed between 2012 and 2015. The most prevalent types of treatment were surgical, with a predominance of quadrantectomy (59\%), and most were undergoing endocrine therapy (71\%). The sociodemographic and clinical data are presented in Table 1.

Table 1 - Sociodemographic and clinical characteristics, São Paulo, Brazil, 2016

\begin{tabular}{|c|c|}
\hline Characteristics & $\mathbf{n}$ \\
\hline $\begin{array}{l}\text { Age (Min - Max) } \\
\text { M (SD) }\end{array}$ & $\begin{array}{c}35-88 \\
59,1(10,6)\end{array}$ \\
\hline $\begin{array}{l}\text { Marital Status } \\
\text { Single } \\
\text { Married } \\
\text { Divorced } \\
\text { Widower }\end{array}$ & $\begin{array}{l}18(18) \\
50(50) \\
22(22) \\
10(10)\end{array}$ \\
\hline $\begin{array}{l}\text { Living together }(\%) \\
\text { Lives alone } \\
\text { Lives with others }\end{array}$ & $\begin{array}{l}17(17) \\
83(83)\end{array}$ \\
\hline $\begin{array}{l}\text { Children (Min - Max) } \\
\text { M (SD) }\end{array}$ & $\begin{array}{c}0-10 \\
2,4(1,8)\end{array}$ \\
\hline $\begin{array}{l}\text { Level of education (\%) } \\
\text { No formal education (\%) } \\
\text { Elementary school } \\
\text { High school } \\
\text { Higher education }\end{array}$ & $\begin{array}{c}8(8) \\
52(52) \\
30(30) \\
10(10)\end{array}$ \\
\hline $\begin{array}{l}\text { Religion }(\%) \\
\text { Catholic } \\
\text { Evangelical Protestant } \\
\text { Spiritist } \\
\text { Atheist } \\
\text { Buddhist }\end{array}$ & $\begin{array}{l}40(40) \\
47(47) \\
8(8) \\
3(3) \\
2(2)\end{array}$ \\
\hline $\begin{array}{l}\text { Social class }(\%) \\
\text { B2 } \\
\text { C1 } \\
\text { C2 } \\
\text { D }\end{array}$ & $\begin{array}{l}11(11) \\
26(26) \\
37(37) \\
26(26)\end{array}$ \\
\hline $\begin{array}{l}\text { Current occupation (\%) } \\
\text { Unemployed } \\
\text { Employed } \\
\text { Retired } \\
\text { Self-employed }\end{array}$ & $\begin{aligned} 39 & (39) \\
18 & (18) \\
38 & (38) \\
5 & (5)\end{aligned}$ \\
\hline $\begin{array}{l}\text { Smoking }(\%) \\
\text { Non-smoker } \\
\text { Ex-smoker } \\
\text { Smoker }\end{array}$ & $\begin{array}{c}73(73 \%) \\
22(22 \%) \\
5(5 \%)\end{array}$ \\
\hline $\begin{array}{l}\text { Alcoholism (\%) } \\
\text { Yes }\end{array}$ & $6(6)$ \\
\hline $\begin{array}{l}\text { Type of cancer }(\%) \\
\text { Ductal carcinoma } \\
\text { Lobular carcinoma } \\
\text { Noninvasive carcinoma } \\
\text { Paget's disease }\end{array}$ & $\begin{aligned} 89 & (89) \\
7 & (7) \\
2 & (2) \\
2 & (2)\end{aligned}$ \\
\hline $\begin{array}{l}\text { Year of diagnosis }(\%) \\
1991-2011 \\
2012 \\
2013 \\
2014 \\
2015\end{array}$ & $\begin{aligned} 24 & (45) \\
21 & (21) \\
29 & (29) \\
21 & (21) \\
5 & (5)\end{aligned}$ \\
\hline $\begin{array}{l}\text { Treatments performed (\%) } \\
\text { Antineoplastic chemotherapy } \\
\text { Radiotherapy } \\
\text { Endocrine therapy } \\
\text { Surgery (quadrantectomy) }\end{array}$ & $\begin{array}{l}45(45) \\
38(38) \\
71(71) \\
59(59)\end{array}$ \\
\hline
\end{tabular}

Note: M: mean; SD: standard deviation. 
Descriptive analysis of the IOC scale showed that the most frequently listed problems were: health worry $(M=4.1, S D=0.9)$, feelings about cancer $(M=3.9, S D=0.8)$, and meaning of cancer $(M=3.6, S D=0.9)$ (Table 2). Overall, mean QoL was 85.8 $(\mathrm{SD}=18.1$ ), with higher scores in the functional well-being subscales $(M=22.3, S D=5.4),(M=22.2, S D=7.8)$ and additional breast issues $(M=24.4, S D=7.9)($ Table 2$)$.

Table 2 - Descriptive data of instruments for measuring the impact of cancer and quality of life on women with breast cancer, São Paulo, Brazil, 2016

\begin{tabular}{lc}
\multicolumn{1}{c}{ Characteristics } & M (SD) \\
\hline IOC Health Worry & \\
Body Changes & $4.1(0.9)$ \\
Feelings about Cancer & $3.0(1.5)$ \\
Negative Self-Evaluation & $3.9(0.8)$ \\
Negative Outlook & $1.8(1.2)$ \\
Meaning of Cancer & $2.8(0.9)$ \\
Concerns about Cancer & $3.6(0.9)$ \\
& $3.0(1.2)$ \\
FACT-B & \\
General & \\
Physical Well-Being & \\
Social/Family Well-Being & $22.8(18.1)$ \\
Emotional Well-Being & $21.5(7.8)$ \\
Functional Well-Being & $19.7(4.6)$ \\
Additional Issues - Breast & $22.3(5.4)$ \\
\hline
\end{tabular}

Note: IOC: Impact of Cancer Scale; FACT-B: Functional Assessment of Cancer Therapy-Breast Cancer; M: mean; SD: standard deviation.

The final linear regression model identified significant associations between shorter survival time interval (reference year of diagnosis) and the presence of health worry $(B=1.27, S D=0.5, p=$ $0.02)$, as well as between the end of antineoplastic chemotherapy (reference year is the last cycle) and negative self-evaluation $(B=$ $1.82, \mathrm{SD}=0.63, \mathrm{p}=0.01)$. The lower-income classes, $\mathrm{C}$ and $D$, were associated with lower levels of health worry $(B=0.23$, $S D=0.09, p=0.01)$, a lower level of concern about cancer $(B$ $=0.24, \mathrm{SD}=0.13, \mathrm{p}=0.05)$, and greater negative outlook on their experience with the disease process $(B=0.24, S D=0.90, p$ $=0.009)$. However, higher levels of education predicted positive outlook on cancer ( $B=-0.11, S D=0.52, p=0.03$ ) (Table 3 ). In general, higher QoL scores (FACT-B) were associated with proximity to the year of diagnosis, and lower QoL scores $(p<0.05)$ were identified in the subscales body changes, negative self-evaluation and concerns with cancer (Table 3).

Table 3 - Covariables associated with quality of life, São Paulo, Brazil, 2016

\begin{tabular}{lccccc}
\hline \multicolumn{1}{c}{ Covariables } & B & SD & $\boldsymbol{\beta}$ & t & $\boldsymbol{p}$ value \\
\hline FACT-B & & & & & \\
$\quad$ Body Changes & -5.87 & 1.47 & -0.36 & -3.99 & 0.001 \\
$\quad$ Negative Self-Evaluation & -4.48 & 1.85 & -0.23 & -2.42 & 0.02 \\
Concerns about Cancer & -3.94 & 1.88 & -0.19 & -2.09 & 0.03 \\
\hline
\end{tabular}

Note: B: coefficient; SD: standard deviation; FACT-B: Functional Assessment of Cancer Therapy-Breast Cancer.

\section{DISCUSSION}

The present article presented a detailed discussion of the sociodemographic and clinical variables, which contributes to characterizing a population that is not often studied in Brazil, and to interpret perceptions of QoL and impact of cancer. Thus, the participants were women between the ages of 35 and 88 , most of them in their fifties, and with a histological diagnosis of ductal carcinoma. These findings are consistent with the international literature, as well as the main modalities of treatments performed ${ }^{(1)}$.

Almost all the women some sort of faith and spirituality, characteristic of Brazilian culture that can be associated with coping mechanisms, a potential influence on the perception of QoL and well-being ${ }^{(14)}$. In addition, most patients declared "living with other people", suggesting a possible source of social, emotional and instrumental support. However, the quality of such support needs to be further explored in other studies, because it is an important resource for breast cancer survivors, who may present lowered self-esteem and self-preservation ${ }^{(10-15)}$.

Accurately describing the context of patients diagnosed with cancer, especially economically active adults, can produce important reflections relative to the planning of qualified care throughout the cancer development process. It can help increase the expectations of disease-free survival and favor the recovery of economic activity, positively impacting the family and society's economy ${ }^{(16)}$. Thus, in the present study, it is worth noting the low purchasing power of most of the participants, with the predominance of social classes $C$ and $D$, economic inactivity, worsened by low levels of education, illiteracy, and high average number of children.

The studied population is vulnerable and does not have access to effective public health policies. The findings presented here ratify the relevance of providing ample support, providing cancer patients with the necessary social subsidies during and after treatment, including incentives to resume education and work activities ${ }^{(15)}$. In addition, educational and multidisciplinary support is necessary to understand the illness process, overcome adversities (economic, social, familial) and meet demands for self-care at all stages, from diagnosis to follow-up in either chronic or disease-free conditions ${ }^{(17-18)}$.

The first two years of follow-up tend to be perceived as lacking in terms of information and care, an association that was also a finding of the present investigation. Systematically designed, implemented and evaluated programs are essential for all types of populations, including and making associations with information about the stages of cancer - early detection, diagnosis, treatment, survival, progression, end-of-life - and that generate decision-making skills (self-management), with consequent improvements in QoL and the achievement of well-being ${ }^{(7-8,19)}$.

Corroborating the importance of socioeconomic findings in relation to impact of cancer, women with greater economic and educational vulnerability expressed less concerns about health and cancer, in addition to a negative outlook on the experience of illness. These data highlight the importance of educational measures that address these risk factors in the period following treatment, when these women tend to resume or acquire new 
risk behaviors, such as those that lead to obesity, maintaining a sedentary lifestyle, and smoking ${ }^{(18-19)}$.

A collaborative study conducted in the USA ${ }^{(20)}$ with more than 20,000 women aimed to evaluate the smoking habits of women before and after the diagnosis of breast cancer. The results showed that approximately $10 \%$ of the women who smoked at the time of diagnosis continued to smoke. The data stress the importance of quitting smoking, because it enhances the risk of death due to cancer, and leads to a greater number of deaths due to cardiovascular and respiratory diseases among survivors ${ }^{(20)}$. It is assumed that the surviving women in the present study are at risk of becoming ill and even dying; thus, an accurate assessment of habits is important to define subsequent counseling for behavior change.

Still on the results of the present study, women with a shorter follow-up time, with higher income, and with higher educational levels expressed negative self-evaluation, greater concern with cancer and health, and a less negative outlook on cancer. Feelings of concern can be considered positive when they foster the adoption of healthy behaviors and attitudes, search for information, adherence to routine health check-ups and screening for cancers (secondary to treatment or others) and other diseases that can affect cancer survivors. However, it is important to emphasize the need for adequate multiprofessional care to help these women and their relatives/caregivers to be informed and have adequate support to overcome doubts, fears, uncertainties about body changes, late signs and symptoms of treatment, and the illness itself ${ }^{(5,7,9)}$.

In addition, impact of cancer on body changes and negative self-evaluation was significantly associated with lower QoL. The lowest QoL scores were found in the body changes, negative self-evaluation, and concern about cancer sub-scales. These data are similar to those described in other studies and can be explained by the sequelae of therapies ${ }^{(4,10-11)}$. The type of surgery performed, for example, regardless of extension, impacts these women's self-esteem and self-image, in addition to how they position themselves and relate to the world. Other signs and symptoms may persist in the posttreatment period, such as lymphedema, pain, insomnia, depression, anxiety and other causes of functional impairment ${ }^{(8,19)}$.

The repercussions of breast cancer among the surviving women in this study were consistent with those described in similar investigations, especially in studies involving populations with economic, socio-environmental and cultural vulnerabilities ${ }^{(4-18)}$. Vulnerable population groups require certain care needs regarding cancer survival. Future studies should include a contextualized analysis of these factors, which impact the QoL and well-being of vulnerable individuals, favoring the implementation of more comprehensive and potentially efficient public policies ${ }^{(10)}$.

In sum, even though developing countries such as Brazil still face many challenges in diagnosing and treating cancer, the growth in the number of survivors is a reality that cannot be neglected.

\section{Study limitation}

The present investigation generated important data about the studied women breast cancer survivors. However, the use of a non-probabilistic sample in a single outpatient public service located in one Brazilian state with greater medical and hospital care resources to treat breast cancer limits the generalization of our findings. New studies are recommended to include uninvestigated variables such as environmental conditions, range of social roles, physical activity, comorbidities, uncertainties, and level of anxiety and depression.

Contributions to the area of nursing, health or public policy

The study reveals care demands of breast cancer survivors that can help in the planning and adoption of programs that provide short-, medium- and long-term individualized and systematic care, covering both healthcare education and delivery.

\section{CONCLUSION}

The study identified that women breast cancer survivors have good QoL; however, they report a significant impact of cancer on some aspects of their lives. Economic and educational vulnerability was found to be significantly associated with lower levels of concern with health and cancer, in addition to a negative outlook on the experience of illness. Higher education levels predicted a positive outlook on cancer. Furthermore, lower QoL scores were associated with an impact on the body changes, negative self-evaluation, and concern with cancer subscales, pointing to potential unmet needs in this population during outpatient follow-up.

\section{FUNDING}

Study developed with the support of a scholarship from the Scientific Initiation Program, funded by the National Council of Scientific and Technological Development, CNPq, 2015-2016.

\section{REFERENCES}

1. Miller KD, Siegel RL, Lin CC, Mariotto AB, Kramer JL, Rowland JH, et al. Cancer treatment and survivorship statistics, 2016. CA Cancer J Clin[Internet]. 2016[cited 2017 Mar 20];66(4):271-89. Available from: https://doi.org/10.3322/caac.21349

2. Instituto Nacional do Câncer José de Alencar. CANCERES Estimativa 2016: incidência de câncer no Brasil[Internet]. Rio de Janeiro: INCA; 2015[cited 2017 Oct 21]. Available from: http://www.inca.gov.br/wcm/dncc/2015/estimativa-2016.asp

3. Cecilio AP, Takakura ET, Jumes JJ, Santos JW, Herrera AC, Victorino VJ, et al. Breast cancer in Brazil: epidemiology and treatment challenges. Breast Cancer[Internet]. 2015[cited 2017 Oct 21];7:43-9. Available from: https://www.ncbi.nlm.nih.gov/pmc/articles/ PMC4317062/ 
4. Ansa B, Yoo W, Whitehead M, Coughlin S, Smith S. Beliefs and behaviors about breast cancer recurrence risk reduction among African American breast cancer survivors. Int J Environ Res Public Health[Internet]. 2015[cited 2017 Oct 21];13(1):46. Available from: https://doi.org/10.3390/ijerph13010046

5. Ness S, Kokal J, Fee-Schoroeder K, Novotny P, Satele D, Barton D. Concerns across the survivorship trajectory: results from a survey of cancer survivors. Oncol Nurs Forum[Internet]. 2013[cited 2017 Mar 19];40(1):35-42. Available from: https://doi.org/10.1188/13. ONF.35-42

6. Surbone A, Tralongo P. Categorization of cancer survivors: why we need it. J Clin Oncol[Internet]. 2016 [cited 2017 Mar 19];34(28):3372-4. Available from: https://doi.org/10.1200/JCO.2016.68.3870

7. Ellegaard MB, Grau C, Zachariae R, Bonde Jensen A. Fear of cancer recurrence and unmet needs among breast cancer survivors in the first five years: a cross-sectional study. Acta Oncol[Internet]. 2017[cited 2017 Mar 19];56(2):314-20. Available from: https:// doi.org/10.1080/0284186X.2016.1268714

8. Miyashita M, Ohno S, Kataoka A, Tokunaga E, Masuda N, Shien T, et al. Unmet information needs and quality of life in young breast cancer survivors in Japan. Cancer Nurs[Internet]. 2015[cited 2017 Mar 19];38(6):E1-E11. Available from: https://doi.org/10.1097/ NCC.0000000000000201

9. Cheng KKF, Wong WH, Koh C. Unmet needs mediate the relationship between symptoms and quality of life in breast cancer survivors. Supp Care Cancer[Internet]. 2016[cited 2017 Feb 11];24(5):2025-33. Available from: https://doi.org/10.1007/s00520-015-2994-0

10. Lopez-Class M, Gomez-Duarte J, Graves K, Ashing K. A contextual approach to understanding breast cancer survivorship among Latinas. Psychooncol[Internet]. 2012[cited 2017 Feb 11];21:115-24. Available from: https://doi.org/10.1002/pon.1998

11. Zebrack BJ, Ganz PA, Bernaards CA, Petersen L, Abrahan L. Assessing the impact of cancer: development of a new instrument for long-term survivors. Psychooncol[Internet]. 2006[cited 2017 Feb 11];15(5):407-21. Available from: https://doi.org/10.1002/pon.963

12. Mendes TL, Santos EM. Adaptação transcultural do instrumento Impacto do Câncer em sobreviventes de câncer colorretal: instrumento para avaliação da qualidade de vida[Dissertação]. São Paulo: Fundação Antônio Prudente; 2011.

13. Oliveira IS, Costa LCM, Manzoni ACT, Cabral CMN. Assessment of the measurement properties of quality of life questionnaires in Brazilian women with breast cancer. Braz J Phys Ther[Internet]. 2014[cited 2017 Feb 11];18(4):372-83. Available from: https:// doi.org/10.1590/bjpt-rbf.2014.0045

14. Mello ML, Oliveira SS. Health, religion and culture: a dialogue based on afro Brazilian customs. Saúde Soc[Internet]. 2013[cited 2017 Feb 11];22(4):1024-35. Available from: http://dx.doi.org/10.1590/S0104-12902013000400006

15. Hasson-Ohayon I, Tuval-Mashiach R, Goldzweig G, Levi R, Pizem N, Kaufman B. The need for friendships and information: dimensions of social support and posttraumatic growth among women with breast cancer. Palliat Supp Care[Internet]. 2016[cited 2017 Feb 20];14(4):387-92. Available from: https://doi.org/10.1017/S1478951515001042

16. Guy GP, Donatus U, Ekwueme K, Yabroff R, Dowling EC, Li C, et al. Economic burden of cancer survivorship among adults in the United States. J Clin Oncol[Internet]. 2013[cited 2017 Feb 20];31(30):3749-57. Available from: https://doi.org/10.1200/ JCO.2013.49.1241

17. Yabroff KR, Dowling EC, Guy GP, Banegas MP, Davidoff A, Han X, et al. Financial hardship associated with cancer in the United States: findings from a population-based sample of adult cancer survivors. J Clin Oncol[Internet]. 2016[cited 2017 Feb 20];34(3):25967. Available from: https://doi.org/10.1200/JCO.2015.62.0468

18. Martin DN, Lam TK, Brignole K, Ashing KT, Blot WJ, Burhansstipanov L, et al. Recommendations for cancer epidemiologic research in understudied populations and implications for future needs. Cancer Epidemiol Biomarkers Prev[Internet]. 2016 [cited 2017 Feb 20];25(4):573-80. Available from: https://doi.org/10.1158/1055-9965.EPI-15-1297

19. Tan AS, Nagler RH, Hornik RC, DeMichele A. Evolving information needs among colon, breast, and prostate cancer survivors: results from a longitudinal mixed-effects analysis. Cancer Epidemiol Biomarkers Prev[Internet]. 2015[cited 2017 Feb 20];24(7):1071-8. Available from: https://doi.org/10.1158/1055-9965.EPI-15-0041

20. Passarelli MN, Newcomb PA, Hampton JM, Trentham-Dietz A, Titus LJ, Egan KM, et al. Cigarette smoking before and after breast cancer diagnosis: mortality from breast cancer and smoking-related diseases. J Clin Oncol[Internet]. 2016 [cited 2017 Feb 20];34(12):1315-22. Available from: https://doi.org/10.1200/JCO.2015.63.9328 